\title{
Viabilidade do uso de placa pré-moldada de concreto em casas no estado do Tocantins
}

A industrialização da construção civil, através do Concreto Pré-Moldado, vem promovendo a nível nacional e internacional um grande avanço na qualidade e eficiência dos canteiros de obras, pois com alto padrão de controle ao longo de sua cadeia produtiva, materiais de boa qualidade e mão-de-obra capacitada, as obras civis tornaram-se mais organizadas e seguras. Este trabalho tem como objetivo a análise de trabalhos voltados para os painéis pré-moldados de concreto utilizados em residências, trazendo a parte orçamentaria para nossa região, visando ainda verificar a viabilidade do uso de tal metodologia construtiva no estado do Tocantins, a fim de contribuir para um melhor desempenho da técnica adotada, bem como explanar o método executivo dos painéis em comparação a casas de alvenaria convencional. Os dados obtidos apresentaram uma economia para o sistema pré-moldado de $9,75 \%$. Tornando assim o sistema de execução em prémoldados uma alternativa totalmente viável em comparação ao método convencional de bloco cerâmico. 0 intuito deste trabalho foi contribuir de forma significativa sobre a disposição de informações a respeito do emprego do método construtivo de painéis de vedação de concreto armado empregados na construção de residências no estado do Tocantins.

Palavras-chave: Pré-moldados; Painéis de concreto; Palmas.

\section{Feasibility of the use of precast concrete plate in houses in the state of Tocantins}

The industrialization of civil construction, through Pre-Molded Concrete, has been promoting at national and international level, a great advance in the quality and efficiency of construction sites, because with high standards of control throughout its production chain, good quality materials and skilled labor, civil works have become more organized and safer. This work aims to analyze works aimed at precast concrete panels used in homes, bringing the budget part to our region, aimin to verify the feasibility of using such constructive methodology in the state of Tocantins, in order to contribute for a better performance of the adopted technique, as well as to explain the executive method of the panels in comparison to conventional masonry houses. The data obtained will be extremely impotent for future implementations of this system, presenting more significant results, as well as establishing the economic, technical and operational differentials between the conventional method of ceramic block and that of precast plates. It is hoped that this work can contribute significantly to the provision of information regarding the use of the construction method of reinforced concrete fence panels used in the construction of homes in the state of Tocantins.

Keywords: Pre-molded; Concrete panels; Palmas.

Topic: Engenharia Civil

Reviewed anonymously in the process of blind peer
Received: $17 / 12 / 2020$

Approved: $10 / 03 / 2021$
Wanderson Caetano de Oliveira

Instituto Tocantinense Presidente Antônio Carlos, Brasil

http://lattes.cnpq.br/0522597005325858

wandersoncaetano_@hotmail.com

Rafaella Oliveira Guimarães Santos

Instituto Tocantinense Presidente Antônio Carlos, Brasil

http://lattes.cnpq.br/200687031653498

wandersoncaetano_@hotmail.com
Referencing this:

OLIVEIRA, W. C.; SANTOS, R. O. G.. Viabilidade do uso de placa prémoldada de concreto em casas no estado do Tocantins. Engineering Sciences, v.9, n.1, p.53-67, 2021. DOI:

http://doi.org/10.6008/CBPC2318-3055.2021.001.0006 


\section{INTRODUÇÃO}

A indústria da construção civil é vista como um setor conservador em comparação com outros sistemas produtivos industriais (PAULANI, 2008). A baixa produtividade, de acordo com o mesmo autor, o desperdício exagerado de materiais, o ritmo lento e o baixo controle de qualidade são os principais aspectos que contribuem para este cenário do setor. Nesse contexto, a utilização de elementos pré-moldados é uma opção eficiente para a redução da ociosidade das obras civis.

A industrialização da construção civil, através do Concreto Pré-Moldado, vem promovendo a nível nacional e internacional um grande avanço na qualidade e eficiência dos canteiros de obras, pois com alto padrão de controle ao longo de sua cadeia produtiva, materiais de boa qualidade e mão-de-obra capacitada, as obras civis tornaram-se mais organizadas e seguras.

De acordo com El Debs (2000) a utilização do concreto pré-moldado (CPM), e as suas respectivas estruturas formadas pelos elementos pré-moldados recebem a denominação de estruturas de concreto prémoldado. Desse modo, partes da construção seriam feitas em melhores condições que as do local e depois montadas, como parte do processo construtivo.

O grande sucesso do pré-moldado na automação industrial vai além do processo de fabricação, existem diversos ganhos produtivos no transporte, montagem, métodos de controle e inspeção, criação de novos produtos e no controle dos impactos ambientais provocados pelo processo industrial (PIGOZZO et al., 2006).

Neste sentido, o principal propósito desse trabalho é analisar o panorama atual de pesquisas referentes ao uso de placas pré-moldadas em residências, trazendo a parte orçamentaria para nossa região, visando ainda verificar a viabilidade do uso de tal metodologia construtiva no estado do Tocantins por meio de levantamento orçamentário utilizando como base no SINAPI (Sistema Nacional de Preços e Índices para a Construção Civil). Os dados obtidos serão de suma importância para futuras implementações deste sistema, apresentando resultados mais favoráveis, bem como estabelecer os diferenciais econômicos, técnicos e operacionais entre os mesmos.

\section{METODOLOGIA}

A presente pesquisa trata-se de uma revisão bibliográfica descritiva e exploratória, desenvolvida a partir de materiais publicados em artigos, visando o aprofundamento do estudo em questão. De acordo com Prodanov et al. (2013), a pesquisa descritiva apresenta uma análise juntamente com uma verificação em relação às aplicações de procedimentos e técnicas em virtude na pesquisa.

Nesta revisão de literatura foram utilizados artigos das bases de dados Scielo e Google Acadêmico. Para a pesquisa foram selecionados artigos no idioma português do ano de 2017 e 2018. Utilizaram-se para as buscas as palavras-chave: Pré-moldados, Métodos Construtivos, Habitação, Painéis Pré-Moldados Autoportantes de Concreto Armado.

Primeiramente, selecionaram-se cinco trabalhos que falam acerca da temática estudada, isto é, da 
viabilidade da utilização das placas pré-moldadas de concreto em residências, realizando estudo comparativo com outros métodos, como alvenaria de bloco cerâmico. Os critérios de inclusão foram à leitura completa dos artigos baseados no ano de publicação e artigo relacionado com o tema. Os critérios de exclusão de estudos foram os que não apresentaram boa qualidade metodológica ou não abordaram diretamente o tema.

Os artigos estudados são apresentados, destacando seus métodos executivos e comparação orçamentária. Com base na bibliografia, foi ainda selecionado um dos artigos que possuía uma maior riqueza de detalhes para tomar como base para elaboração de orçamento com base em valores praticados no estado do Tocantins, levando em consideração com base em valores disponibilizados pelo SINAPI.

\section{RESULTADOS E DISCUSSÃO}

\section{Apresentação dos artigos}

Os artigos selecionados abordam diferentes metodologias construtivas, fazendo descrição de processo executivo e análise de viabilidade econômica.

A Tabela 1 apresenta os artigos usados para este estudo contendo o título, nome dos autores e ano de publicação dos trabalhos selecionados.

Tabela 1: Identificação dos estudos selecionados.

\begin{tabular}{|c|c|c|c|}
\hline Item & Título & Autor & Ano \\
\hline EI & $\begin{array}{l}\text { Comparação de custos entre a utilização de alvenaria de blocos cerâmicos e painéis pré- } \\
\text { moldados de concreto para construção de unidades habitacionais unifamiliares }\end{array}$ & $\begin{array}{l}\text { Ronielle da Silva } \\
\text { Barbosa }\end{array}$ & 2018 \\
\hline Ell & $\begin{array}{l}\text { Construção residencial unifamiliar em paredes de concreto } \\
\text { Pré-moldadas: comparativo entre métodos tradicional } \\
\text { (alvenaria em bloco cerâmicos) e pré-moldados }\end{array}$ & $\begin{array}{l}\text { Fernando Martins de } \\
\text { Souza e } \\
\text { Lucas Machado Rufino }\end{array}$ & 2017 \\
\hline ElII & $\begin{array}{l}\text { Estudo comparativo de custo entre alvenaria estrutural, paredes de concreto armado e } \\
\text { alvenaria em painéis modulares. }\end{array}$ & $\begin{array}{l}\text { Alex Márcio Cabral do } \\
\text { Rosário }\end{array}$ & 2017 \\
\hline EIV & $\begin{array}{l}\text { Estudo comparativo entre os sistemas construtivos: alvenaria estrutural e painéis pré- } \\
\text { moldados autoportantes de concreto armado }\end{array}$ & $\begin{array}{l}\text { Ederson } \\
\text { Rogoski }\end{array}$ & 2018 \\
\hline EV & $\begin{array}{l}\text { A Utilização Do Pré-Moldado Em Edificações } \\
\text { Residenciais }\end{array}$ & $\begin{array}{l}\text { Wenderson Matricardi } \\
\text { Rodrigues }\end{array}$ & 2018 \\
\hline
\end{tabular}

\section{Processos Executivos}

Referente aos processos executivos, elaborado com base no que os autores relataram ao longo de seus trabalhos, apenas três destes apresentaram processo executivo dos elementos pré-moldados, por essa razão apenas os trabalhos (EI), (EII) e (EIV) serão descritos neste trabalho. Cada trabalho detalha diferentemente as etapas do método executivo.

\section{Resultados da pesquisa EI (BARBOSA, 2018)}

O trabalho de Barbosa (2018), desenvolvido na cidade de Patos-PB, com uma residência de $80 \mathrm{~m}^{2}$ comparou os custos para execução de uma residência em bloco cerâmico e placa pré-moldada de concreto. Através desta comparação foi descrito o processo executivo em placa pré-moldada. Primeiramente o autor descreveu o método de execução das placas, dados estes retirados da revista TÉCHNE, processo este da fabricação das placas, ele também faz uma rápida e simples descrição do encaixe do mesmo. 
Limpeza e aplicação do desmoldante nas formas e o posicionamento das armaduras (Figura 1), por último é feito o posicionamento da parte elétrica e hidráulica necessária (Figura 2).

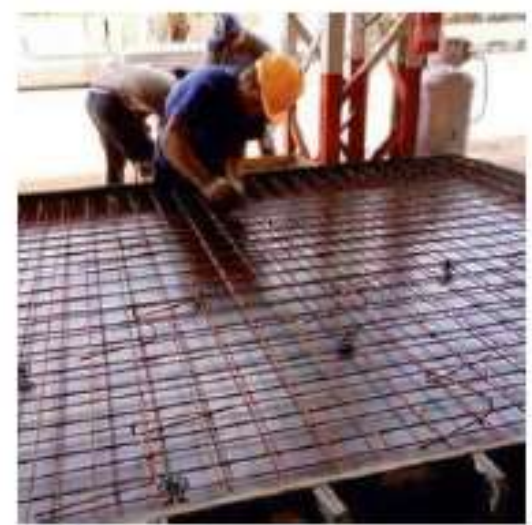

Fonte: TĖCHNE (2016).

Figura 1: Montagem de armadura.

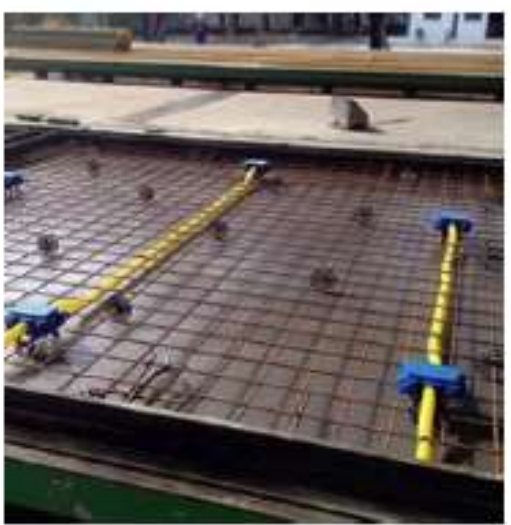

Fonte: TĖCHNE (2016).

Figura 2: Hidráulica e elétrica.

É feita a concretagem, o lançamento do concreto nas formas, como ilustra Figura 3 e 4.

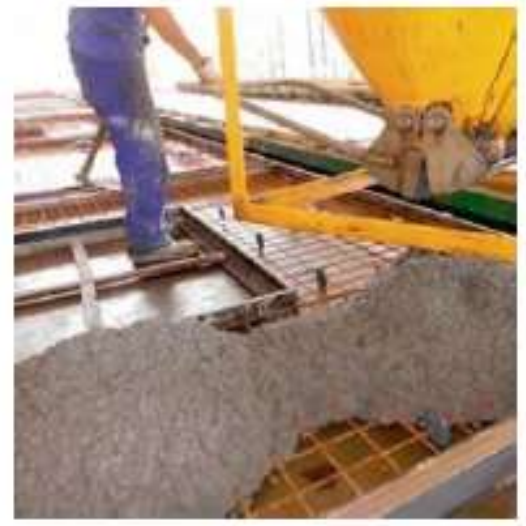

Fonte: TĖCHNE (2016).

Figura 3: Concretagem.

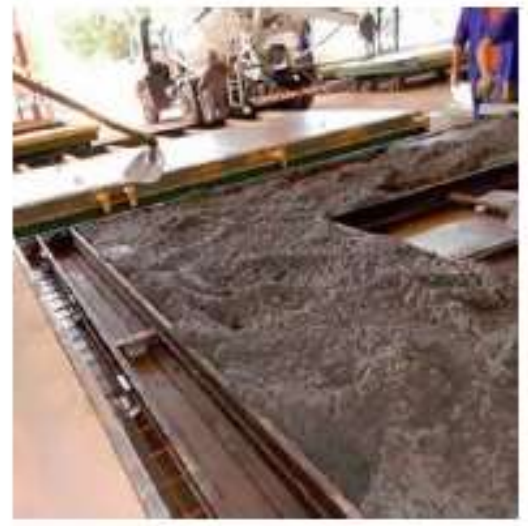

Fonte: TĖCHNE (2016).

Figura 4: concretagem.

O posicionamento das placas precisa de auxilio de equipamento com um caminhão MUNCK (Figura 5).

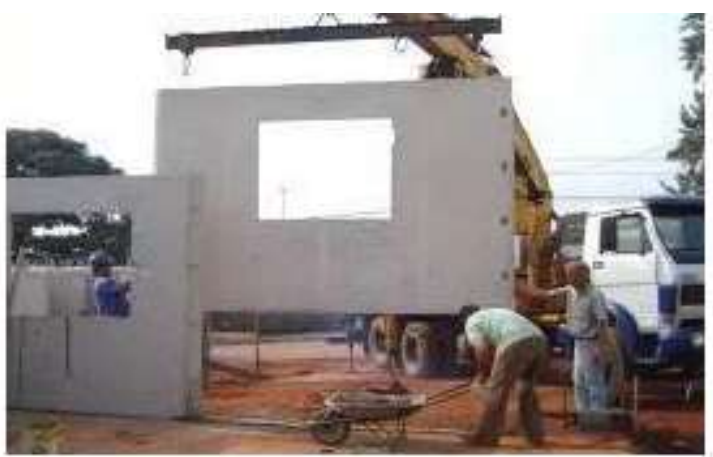

Fonte: PREMONTA, 2018.

Figura 5: Içamento da placa.

Por último o Autor destacou as ligações necessárias para o posicionamento das placas usando como referência DATec 07 (citado por WILK JUNIOR et al., 2016), destaca o fato das placas devem ser colocadas 
sobe uma superfície argamassada para um melhor assentamento na fundação (Figura 6). Para que tenham um bom prumo são colocadas escoras enquanto as mesmas são soldadas e grauteadas (Figura 7).

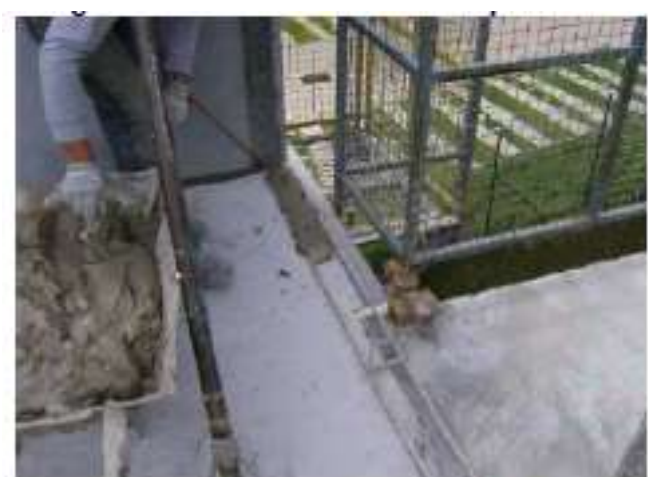

Fonte: DATEC 07 apud JUNIOR 2016.

Figura 6: Massa de assentamento.

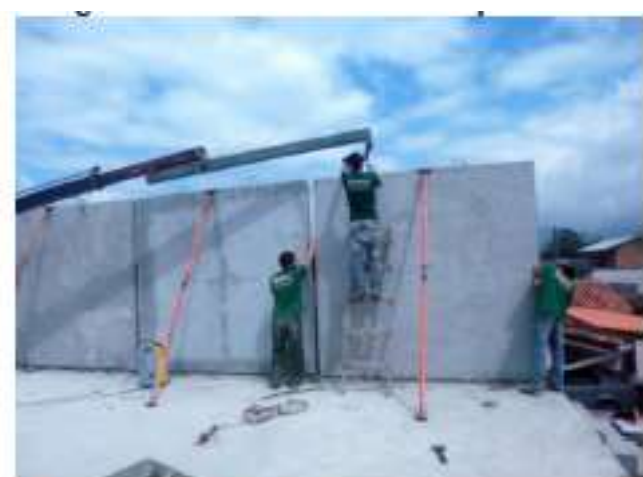

Fonte: PREMONTA, 2018.

Figura 7: Posicionamento da placa.

\section{Resultados da pesquisa Ell (SOUZA et al., 2017)}

O trabalho de Souza et al. (2017), aborda métodos de execução de residências, baseando-se em dados obtidos pela empresa Cymaco Engenharia. A princípio eles destacam como é feita a montagem das paredes, feitas em uma fábrica seguindo as orientações do projeto arquitetônico e que são confeccionadas por uma forma metálica (Figura 8), preparada para classe de agressividade de I a III, ou seja, resistência até $25 \mathrm{Mpa}$.

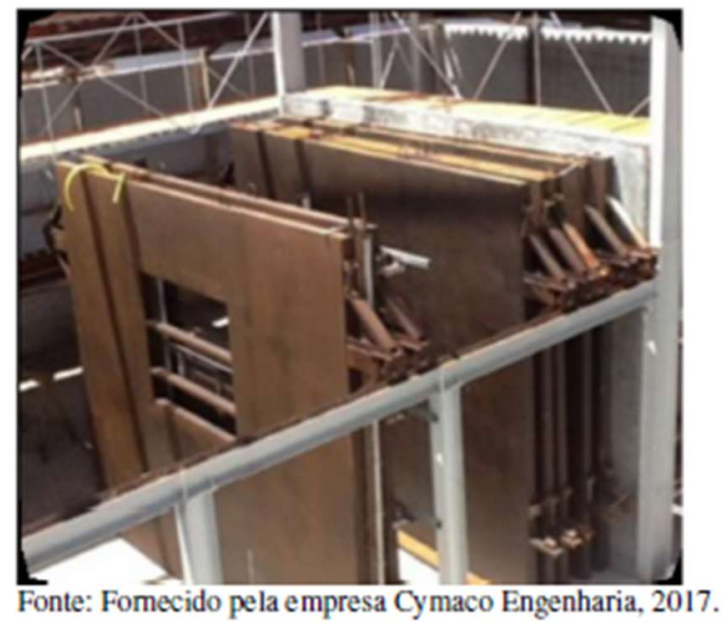

Figura 8: Formas para paredes

Após o processo de execução das placas a mesma passa por um intenso processo de controle de qualidade a fim de obter um produto de qualidade.

No decorrer do trabalho o autor destaca que a produção das placas pode ser feita paralelamente com a execução da fundação, trazendo assim agilidade e rapidez. A escolha da fundação varia de acordo com o solo da região e neste caso optou-se por execução de sapata corrida (Figura 9).

Após a execução da sapata, as placas são transportadas e erguidas para a obra, com auxílio de um guindaste sendo assim posicionados sobre uma camada de argamassa de assentamento é e feito o escoramento para manter o prumo (Figura 10). Segundo Everton Berticelli, e possível fazer a execução de 
uma residência de até $60 \mathrm{~m}^{2}$ em apenas um dia.

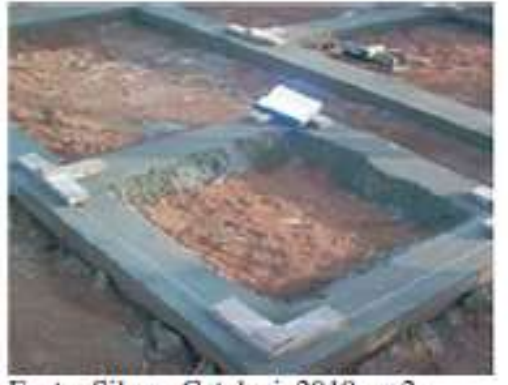

Fonte: Silva e Catelani, 2010 , p. 2.

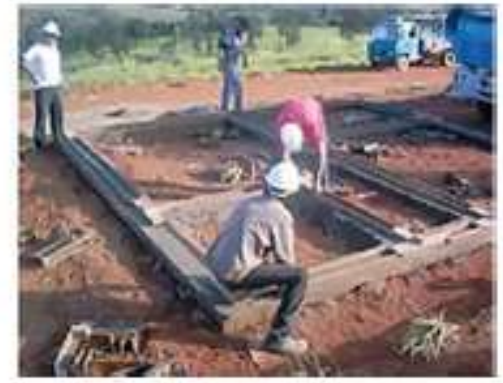

Figura 9: Execução da sapata corrida.
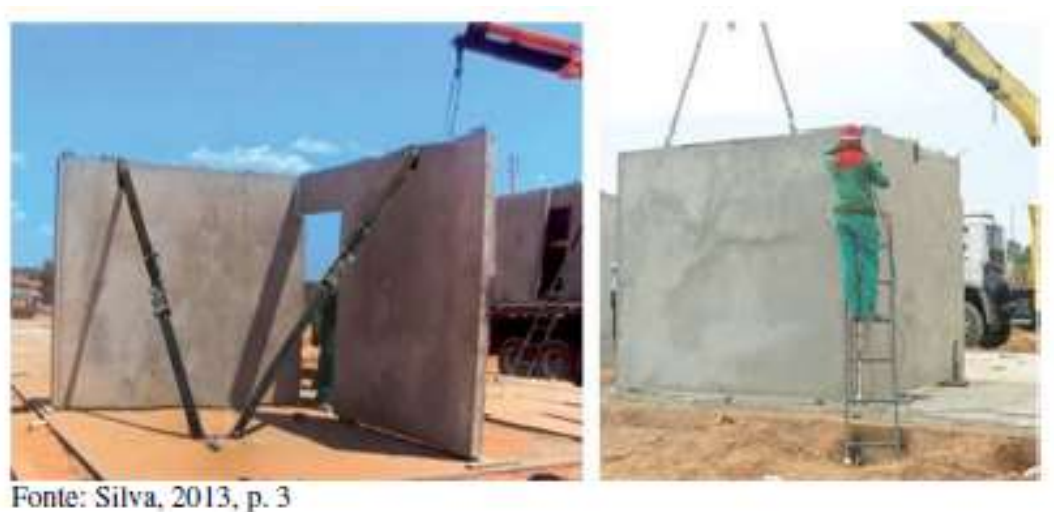

Figura 10: Montagem e assentamento da placa.

Os painéis são ligados através de solda elétrica (Figura 11), a partir de armaduras ao longo de suas extremidades deixadas no processo de execução dos painéis. Logo após é possível preencher as juntas das paredes, fazendo assim o preenchimento com graute (Figura 12).

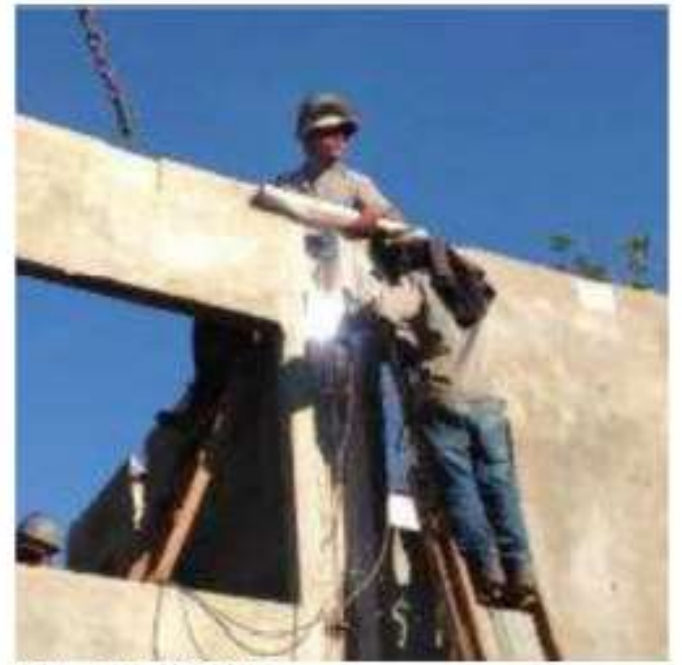

Fonte: SINAT, 2016.

Figura 11: Solda dos painéis.

Ao finalizar este processo nas junções das paredes segundo a empresa Cymaco Engenharia, são formados os pilares recebendo um tratamento especial com selante flexível de polietileno.

Como próximo passo tem-se a laje (Figura 13), que pode ser maciça ou nervurada, podendo ser 
moldada in loco ou pré-moldada, ou podendo optar sem laje apenas com forro de PVC.

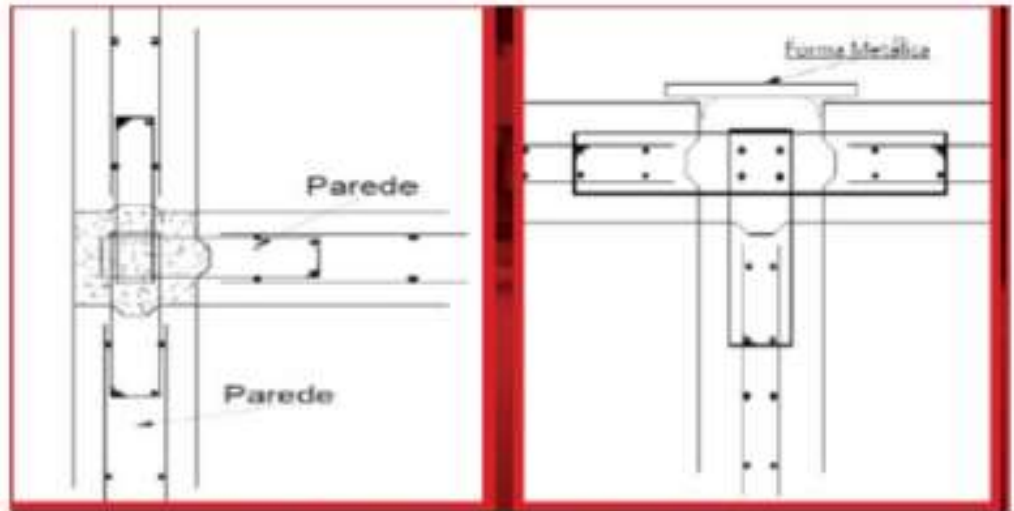

Fonte: Fomecido pela empresa Cymaco Engenharia, 2017.

Figura 12: Junção dos painéis.

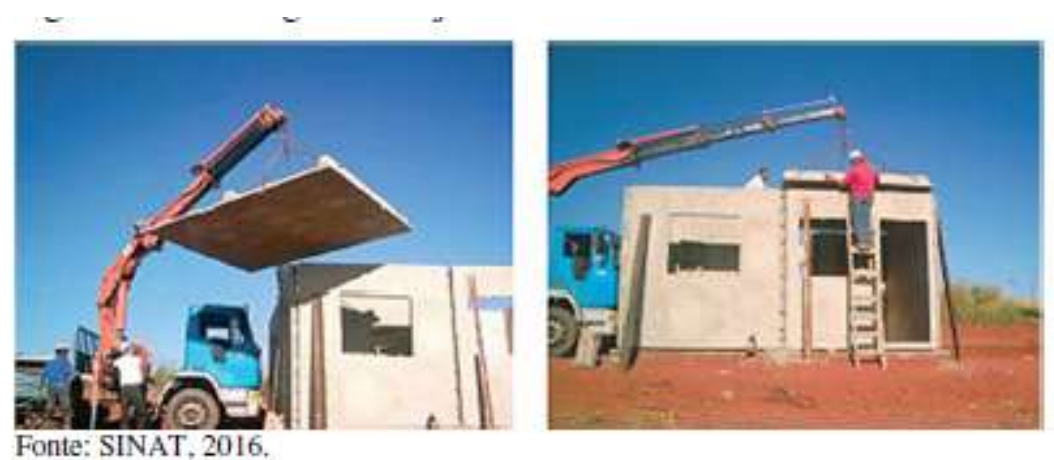

Figura 13: Içamento e posicionamento da laje.

Por fim, o método de cobertura adotado foi o de madeira com a cobertura de telha cerâmica, podendo optar por de fibrocimento. Para última etapa o autor denota que o acabamento como pintura e revestimento cerâmico segue os mesmos métodos padrão usado no tradicional.

\section{Resultados da pesquisa EIV (ROGOSKI, 2018)}

Rogoski (2019) aborda três métodos de execução para uma residência. Tendo em vista este estudo o mesmo descreveu algumas das etapas de execução destes métodos. Como o autor não publicou imagens referentes a esta parte, será feito apenas uma descrição textual, seguindo algumas destas etapas: serviços preliminares, movimentação de terra, infraestrutura (fundações), paredes e etc.

Primeira etapa: Limpeza manual do terreno, locação da obra e ligação de energia e água no local.

Segunda etapa: Movimentação de terra como corte e aterro, escavação manual de vala e execução do alicerce e reaterro das valas.

Terceira etapa: Execução da fundação.

Quarta etapa: Execução da parte drenante, lastro de concreto e revestimento cerâmico do piso.

Quinta etapa: Execução das paredes de painéis pré-moldados foi posicionada formas moldadas in loco em faces internas da parede; em planos de fachada com vãos; logo após armação da parede, após o posicionamento e concretado as formas.

Sexta etapa: Nesta etapa é executada a cobertura, feita em madeira coberta com telha cerâmica, 
feito assim com o método convencional.

Sétima etapa: A Execução do forro é o mesmo já usado no método convencional, forro em PVC, frisado e estrutura de fixação.

Oitava etapa: Assim como a quinta etapa, referente a paredes, está se refere ao revestimento apresentando distinção entre os sistemas. Já para o sistema de pré-moldado é apenas composta por revestimento cerâmico, sendo colocados diretamente nos painéis. Quanto para pintura é composto por dois serviços, tais como aplicação de selador e aplicação da pintura.

\section{Orçamentos}

A partir da análise dos resultados obtidos em cada artigo é possível identificar vantagens e desvantagens dos métodos executivos. Como cada estudo utiliza diferentes propostas de materiais, o presente trabalho apresenta os resultados de cada um deles de maneira individual.

Destes apenas o EllI não possui informações sobre o orçamento. E analisando os dados orçamentários apresentados por cada autor, os resultados serão apresentados com o intuito de reproduzir de maneira sucinta a viabilidade econômica do método no estado do Tocantins.

\section{Resultados da pesquisa EI (BARBOSA, 2018)}

Conforme o trabalho de Barbosa (2018), realizado na cidade de Patos no estado da Paraíba, comparando o sistema construtivo convencional e o método alternativo de pré-moldados de concreto, chegou-se à conclusão que o pré-moldado gera algumas vantagens em relação ao convencional. Primeiramente, destaca-se a questão do tempo de execução da obra (o uso de placas pré-moldadas garante uma execução mais rápida). Além disso, a viabilidade econômica do segundo método é melhor, representando uma economia de cerca de 3,46\%. A área que o autor levou em consideração em sua pesquisa foi de $79,86 \mathrm{~m}^{2}$. Para o levantamento de custos (orçamentação) levou em consideração dados cedidos pela empresa MVCA Empreendimentos e o orçamento via Custo Unitário Básico (CUB) de SINDUSCON-JP para o mês de março do ano de 2018.

O orçamento da obra feita com blocos cerâmicos com os dados concedidos pela MVCA

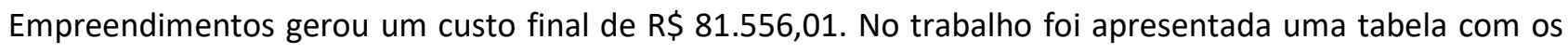
custos previstos em cada etapa de execução da obra, desde os serviços iniciais aos complementares. Para levantar os quantitativos de materiais necessários utilizou-se o programa AutoCad a fim de se obter informações sobre a quantidade de aço necessária, conforme Figura 14.

\begin{tabular}{|c|c|c|c|r|}
\hline \multicolumn{5}{|c|}{ Resumo de aço } \\
\hline Elemento & Bitola & Quantidade & Und & Peso + 10\% (KG) \\
\hline Malha Nervurada Q246 & 5 & 260,24 & $\mathrm{~m}^{2}$ & $1.119,86$ \\
\hline Barras de Contorno & 10 & 514,52 & $\mathrm{~m}$ & 349,20 \\
\hline Barras de Soldagem & 10 & 651,70 & $\mathrm{~m}$ & 442,31 \\
\hline Barras de Içamento & 10 & 132,30 & $\mathrm{~m}$ & 89,79 \\
\hline \multicolumn{7}{|c|}{ Total } & 2001,16 \\
\cline { 2 - 5 }
\end{tabular}

Figura 14: Resumo dos materiais dos painéis pré-moldados. Fonte: Barbosa (2018). 
O custo total desta etapa foi de $\mathrm{R} \$ 23.953,41$. Consideraram-se itens como: desmoldante para formas metálicas a base de óleo vegetal; carpinteiro de formas com encargos complementares; armação de verga e contraverga de alvenaria estrutural; diâmetro de $10 \mathrm{~mm}$. AF_01/2015; pedreiro com encargos complementares, entre outros. A Figura 15 contém a quantidade de concreto previsto na obra.

\begin{tabular}{|c|c|}
\hline \multicolumn{2}{|c|}{ Resumo de Concreto } \\
\hline Elemento & Quantidade $\left(\mathbf{m}^{3}\right)$ \\
\hline Painéis & 26,60 \\
\hline
\end{tabular}

Figura 15: Resumo de concreto. Fonte: Barbosa (2018).

A partir da obtenção do custo final dos painéis, é preciso dividir esse valor pela quantidade total de concreto necessário, assim, obteve-se um valor de $\mathrm{R} \$ \mathbf{8 3 6 , 9 5}$ por $\mathrm{m}^{3}$.

Ao Final do Trabalho comparando os serviços, se chegou a um valor de $\mathrm{R} \$ \mathbf{7 8 . 7 3 9 , 9 0}$ para o prémoldado e o valor para o convencional de $\mathrm{R} \$ \mathbf{8 1 . 5 5 6 , 0 1 .}$

Por fim, o autor conclui que o sistema pré-moldado e viável e que deve ser mais bem aproveitado, pois os custos foram abaixo do convencional, apesar de que o projeto não tinha sido pensando para o uso de pré-moldado. Ressaltando que para obtenção de um orçamento mais realista devem-se levar em consideração os seguintes parâmetros: custos com o posicionamento dos painéis e com o transporte.

\section{Resultados da pesquisa EII (SOUZA et al., 2017)}

Souza et al. (2017) fizeram uma analogia entre dois métodos construtivos alvenaria em blocos cerâmico e pré-moldados. A área construída do projeto analisado foi de $58,26 \mathrm{~m}^{2}$ e se localiza na Rua Tarcísio Vilella, bairro Caçador, na cidade de Capivari de Baixo, em Santa Catarina. O elemento considerado na pesquisa foi o pré-moldado em concreto armado.

O autor apresenta uma tabela contendo os custos gerados em cada etapa construtiva do método tradicional, chegando a um valor final de $\mathrm{R} \$ 77,263,91$. Observa-se ainda que o valor total da obra segundo o autor se aproxime do real final, contudo, outros fatores merecem atenção, como: prazos; eficiência do método construtivo; controle de qualidade; entre outros. Através da tabela foi possível gerar o Figura 16 onde é exposta a relação entre os custos das etapas construtivas (em $\mathrm{R} \$$ ).

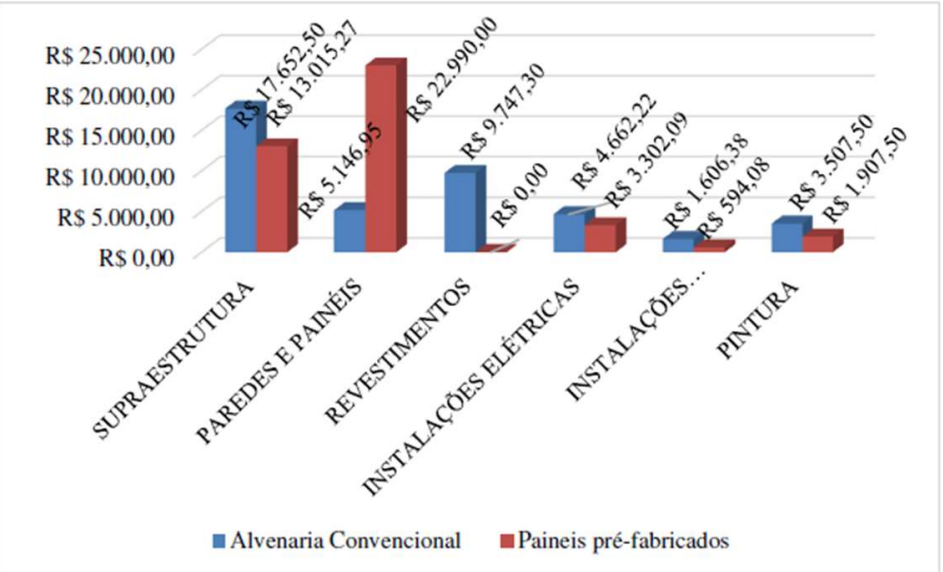

Figura 16: Relação entre os valores das etapas construtivas. Fonte: Souza et al. (2017). 
Com o auxílio da mesma tabela construiu-se também um novo gráfico contendo o percentual de custo de cada etapa em relação ao custo final da obra. Com base nele nota-se que a etapa de painéis se destaca das demais, chegando a um valor de $29,56 \%$.

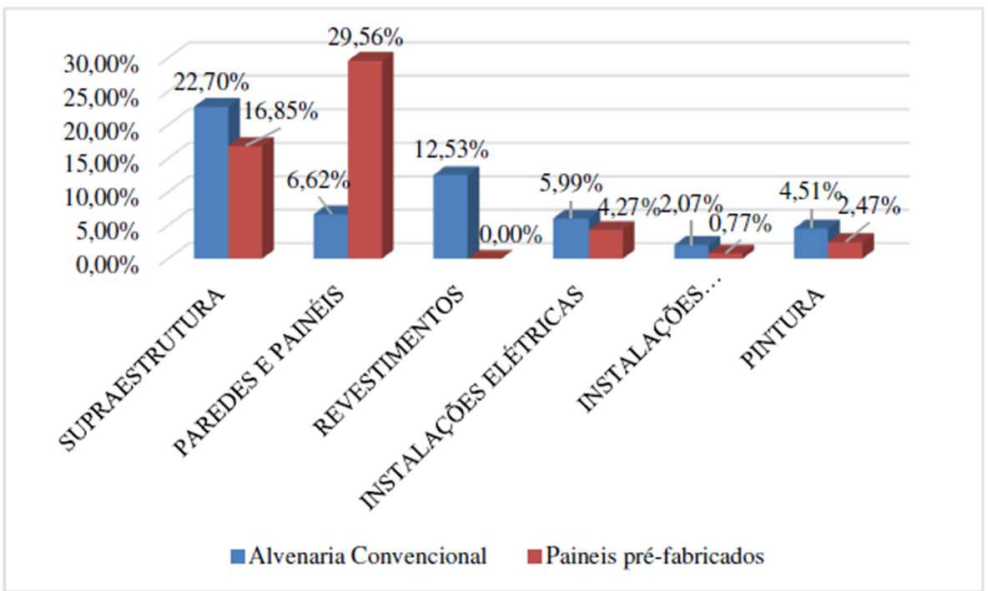

Figura 17: Percentual das etapas em relação ao custo total da obra. Fonte: Souza et al. (2017).

Essa diferença de valor, segundo Souza et al. (2017), pode ser justificada pelo fato de os painéis terem como características um bom controle de qualidade, acabamento, desempenho estrutural, partes de instalações hidráulicas e elétricas e menor prazo de execução. Esses fatos podem gerar economia devido à inexistência de mão de obra e compensar o serviço de outras etapas.

O gráfico a seguir faz uma comparação entre os valores praticados na construção civil no estado de Santa Catarina. Relacionou-se o custo direto por $\mathrm{m}^{2}$ entre os dois métodos construtivos considerados e o CUB-SC para o mês de setembro de 2017, no sistema construtivo convencional.

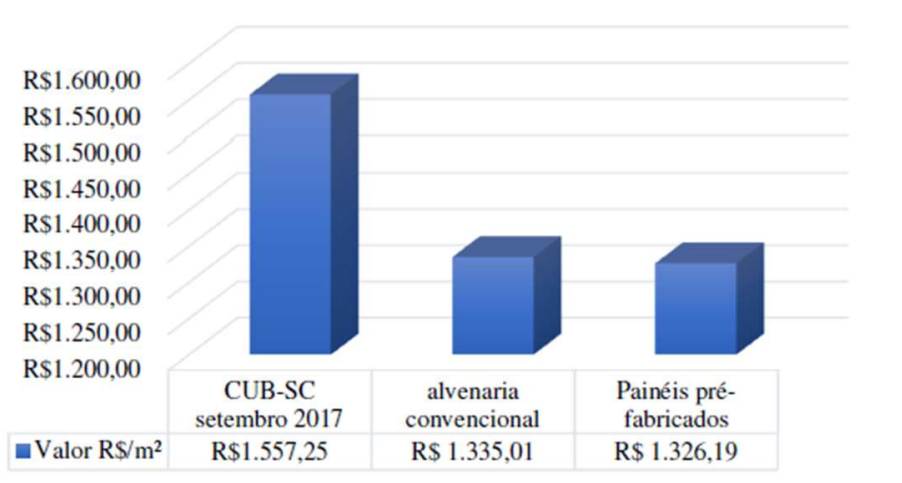

Figura 18: Relação entre os métodos construtivos e o CUB-SC de setembro/2017. Fonte: Souza et al. (2017).

Segundo Souza et al. (2017), a variação verificada no gráfico se justifica devido ao CUB levar em consideração a média de valores praticados na região. Já nos orçamentos considerou-se um elevado padrão de economia, obtendo materiais com valores relativamente menores que os adotados pelo CUB-SC.

Ainda é feita uma análise do tempo de serviço necessário para a execução de cada um dos métodos. No método convencional o tempo de execução foi de 66 dias, já o de painéis pré-moldados, 31 dias. Ou seja, o segundo método provou ser mais viável em questão de tempo, pois, representou uma redução de aproximadamente $53 \%$ em relação ao primeiro.

Ao final o autor chega à conclusão que apesar dos dois métodos terem um valor final aproximado, 
os paneis tiveram o valor final mais econômico e um prazo final menor que o convencional. Tendo o sistema tradicional um valor final de $\mathrm{R} \$ 77.777,82$ enquanto o de painéis um valor de $\mathrm{R} \$ 77.263,91$.

\section{Resultados da pesquisa EIV (ROGOSKI, 2018)}

Conforme Rogoski (2018) foram apresentadas algumas comparações com base no projeto arquitetônico do loteamento Auxiliadora II, localizado na cidade de Santa Rosa, no Estado do Rio Grande do Sul. Foi realizada comparação entre o sistema tradicional de construção - a alvenaria estrutural - e os painéis pré-moldados autoportantes de concreto armado.

Com método de avaliação para a comparação, foram necessários orçamentos para cada sistema baseados nas tabelas e composições do SINAPI. Além dos orçamentos, também se analisou cada sistema quanto ao desempenho térmico da parede, visando às vantagens e desvantagens encontradas no levantamento bibliográfico. A área que o autor levou em consideração em sua pesquisa foi de $36,00 \mathrm{~m}^{2}$.

Ao apresentar as etapas desenvolvidas na orçamentação do sistema construtivo alvenaria estrutural, obteve-se, como resultado final de $\mathrm{R} \$ 44.504,01$.

O sistema construtivo com menor custo final na orçamentação ficou com o sistema construtivo composto de painéis pré-moldados autoportantes de concreto armado, sendo que a diferença tem valor final igual a $\mathrm{R} \$ 3.311,94$, em comparação com os demais sistemas construtivos. Portanto, essa redução no valor final do custo reduzido ocorre devido ao fato de a etapa de revestimento não ter a necessidade de revestimento argamassado, empregando apenas revestimento cerâmico.

De acordo com Rogoski (2018), o custo total da obra para os sistemas construtivos ao final do último procedimento descrito com base nos orçamentos apresenta o menor valor para o sistema de painéis prémoldados, com valor final da obra orçado em $\mathrm{R} \$ 40.180,21$. Já o valor intermediário ficou com o sistema tradicional, que apresentou o valor final de $\mathrm{R} \$ 43.492,15$, e, com valor mais alto, apresenta o orçamento do sistema construtivo alvenaria estrutural, com custo de $\mathrm{R} \$ 44.504,01$.

\section{Resultados da pesquisa EV (RODRIGUES, 2018)}

Conforme o trabalho de Rodrigues (2018) com intuito da utilização do pré-moldado em edificações residenciais levando em consideração uma residência de $42,95 \mathrm{~m}^{2}$, seu levantamento contou com o auxílio de serviços, como das planilhas da SETOP MG e SINAPI e o cálculo estrutural dessa unidade utilizando o software Eberick, a fim de obter os dados quantitativos em alvenaria convencional fornecidos por uma construtora da cidade de Uberlândia-MG referentes ao Residencial Pequis, inserido na faixa 1 do Programa Minha Casa Minha Vida executados em paredes de concreto moldadas in loco.

O orçamento da obra feita com os custos dos sistemas construtivos com os dados concedidos pela

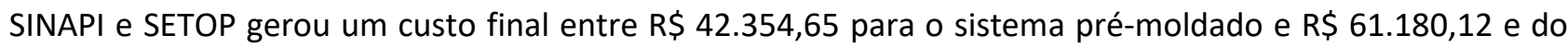
pré-moldado respectivamente. O sistema de paredes de concreto moldadas in loco possui um custo muito mais elevado (cerca de $80 \%$ mais caro) quando comparadas com as paredes de alvenaria convencional. A partir dos custos e área de cada unidade habitacional $\left(42,95 \mathrm{~m}^{2}\right)$, obteve-se o preço por $\mathrm{m}^{2}$ para cada sistema 
construtivo (Figura 19).

O sistema de pré-moldado tem custo menor, em torno de $30 \%$ do valor final da obra, por se tratar de uma parede autoportante. Quanto ao revestimento, a alvenaria estrutural precisa da execução de chapisco, emboço e reboco para então ser aplicado o revestimento vertical ou pinturas resultando em um valor de $70 \%$ mais caro que a parede de pré-moldado que necessita apenas de limpeza com jato d'agua e fechamento de furos que podem ocorrer no decorrer da execução.

\begin{tabular}{|c||c|c|}
\hline \multicolumn{1}{|c|}{ TIENS } & Paredes de Concreto & Alvenaria Convencional \\
\hline Paredes & $\mathrm{R} \$ 7.215,01$ & $\mathrm{R} \$ 2.556,86$ \\
\hline Fundaçâo e Laje & $\mathrm{R} \$ 4.378,81$ & $\mathrm{R} \$ 4.671,69$ \\
\hline Vigas e Pilares & - & $\mathrm{R} \$ 18.489,43$ \\
\hline Esquadrias & $\mathrm{R} \$ 6.475,36$ & $\mathrm{R} \$ 6475,35$ \\
\hline Revestimento & $\mathrm{R} \$ 1.863,36$ & $\mathrm{R} \$ 7878,57$ \\
\hline Pavimentação & $\mathrm{R} \$ 3.313,89$ & $\mathrm{R} \$ 3286,73$ \\
\hline Pintura & $\mathrm{R} \$ 4.108,97$ & $\mathrm{R} \$ 4.220,26$ \\
\hline Cobertura & $\mathrm{R} \$ 4.513,84$ & $\mathrm{R} \$ 4.513,84$ \\
\hline $\begin{array}{c}\text { Instalaçōes hidráulicas e } \\
\text { sanitárias }\end{array}$ & $\mathrm{R} \$ 3.134,93$ & $\mathrm{R} \$ 3.134,93$ \\
\hline $\begin{array}{c}\text { Instalaçōes elétricas, tomadas e } \\
\text { iluminaçōes }\end{array}$ & $\mathrm{R} \$ 6.972,48$ & $\mathrm{R} \$ 6.972,48$ \\
\hline \hline Serviços Finais & $\mathrm{R} \$ 378.00$ & $\mathrm{R} \$ 378,00$ \\
\hline Tor AL & $\mathrm{R} \$ 42.354,65$ & $\mathrm{R} \$ 61.180,12$ \\
\hline
\end{tabular}

Figura 19: Quadro de Custos dos sistemas construtivos.

É importante afirmar, que nos dois métodos fizeram-se a exceção dos serviços preliminares e movimentação de terra e os projetos, elétricos, hidráulicos, fundações e coberturas não foram alterados, assim como os serviços finais.

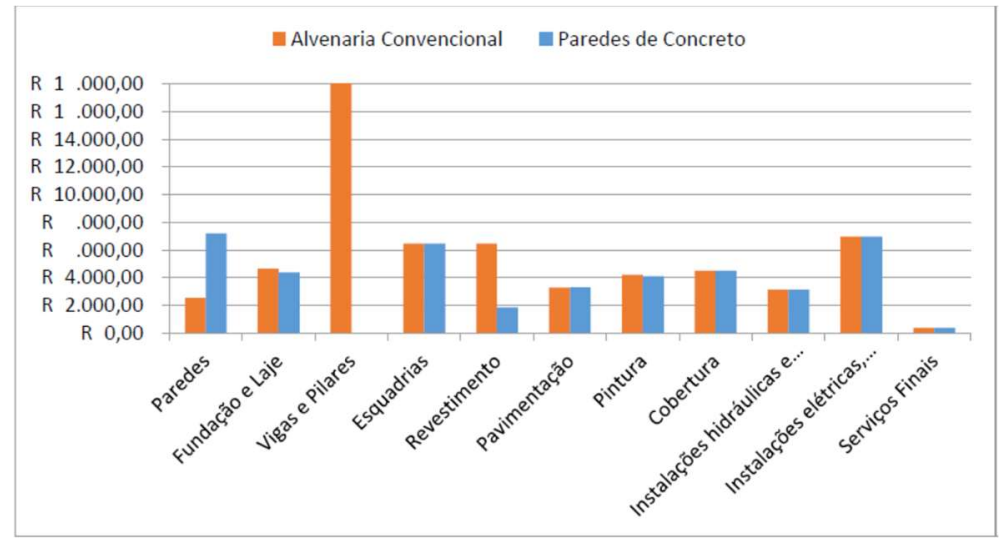

Figura 20: Diagrama comparativo dos custos.

Os dados da tabela de valores do sistema de alvenaria convencional do sistema de paredes são maiores que do sistema de pré-moldado por metro quadrado. A alvenaria convencional gasta aproximadamente quatro vezes mais tempo que o processo construtivo de paredes de concreto. Um autor destacou a possibilidade de aplicação de diferentes sistemas construtivos e ressaltou que as estruturas préfabricadas de concreto devem ser sempre consideradas como uma alternativa nos estudos de viabilidade.

\section{Orçamento Regional}

Para este orçamento, escolheu-se o trabalho Ell (SOUZA et al., 2017) pois se notou que o mesmo segue um método descritivo mais detalhado. Posteriormente comparar este valor a uma residência 
convencional utilizando blocos cerâmicos, considerando o preço disponível para a região utilizando o SINAPI, pois este foi o método utilizado pelos autores para orçamentação do projeto, podemos quantificar o valor por $\mathrm{m}^{2}$ disponível no mesmo. A planta baixa da residência orçada pode ser vista na Figura 21.

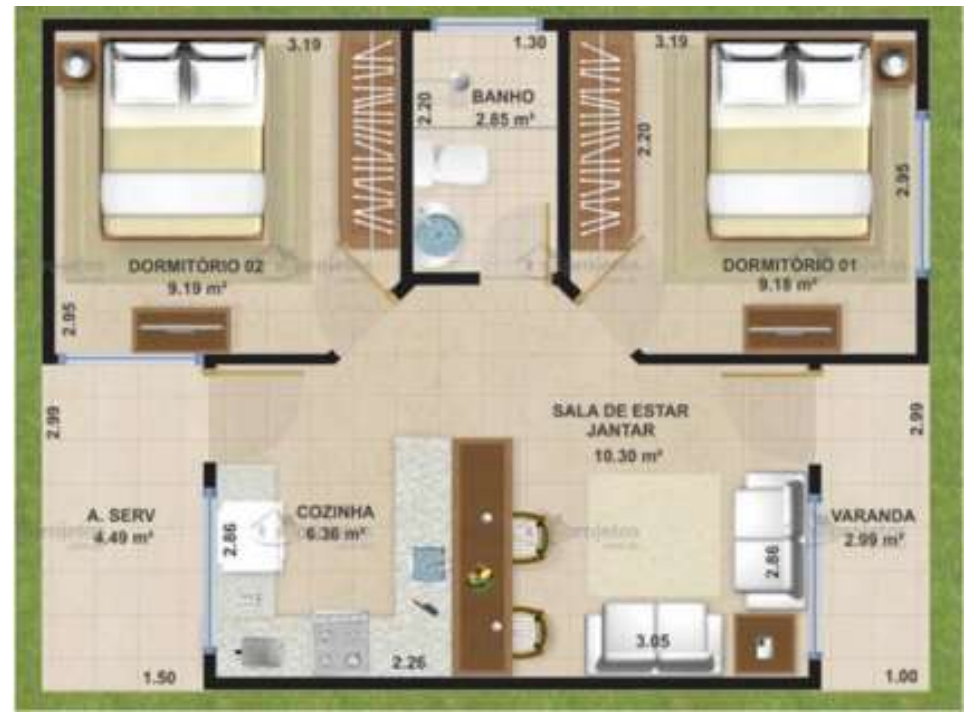

Figura 21: Planta baixa do autor. Fonte: Souza et al. (2017).

Para comparar com alvenaria convencional, o valor foi verificado de acordo com o SINAPI, a qual teve sua emissão no dia 23 de outubro de 2020, a tabela apresentada trata-se de encargos sociais não desonerados para mão de obra.

De acordo com IBGE 2015, o SINAPI caracteriza-se como um sistema nacional de pesquisa de custos e índices da construção civil, apresenta preços e índices de construção civil para cada região.

$\mathrm{Na}$ Figura 22 ilustram-se as etapas que mais apresentaram uma diferença significativa dentre os sistemas construtivos.

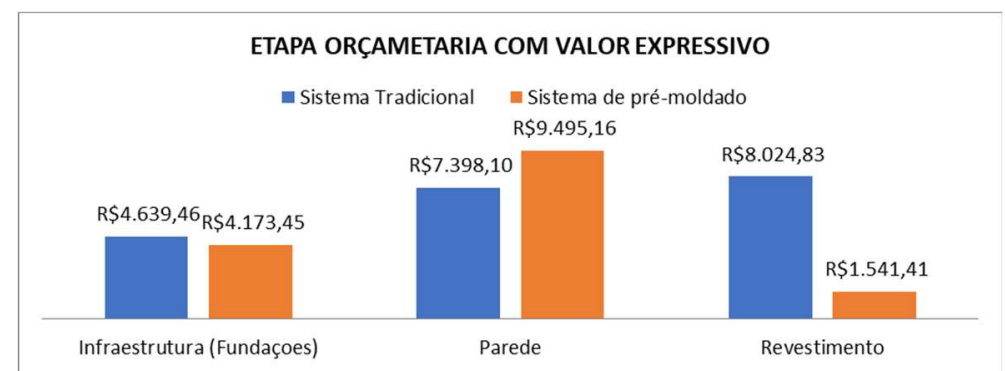

Figura 22: Etapas com diferença significativa entre os métodos construtivos

Especificamente no caso do orçamento regional construído, obteve-se um valor de R\$ 46.794,09 para o sistema tradicional e $\mathrm{R} \$ 42.227,69$ para o que faz uso de painéis pré-moldados autoportantes, como ilustrado na Figura 23. Isso representa uma economia significante de cerca de 9,75\%.

Pode-se observar que há viabilidade econômica, as novas tecnologias sustentáveis trazem vantagens que, no nosso caso torna-se viável a implementação dos elementos pré-moldados. 


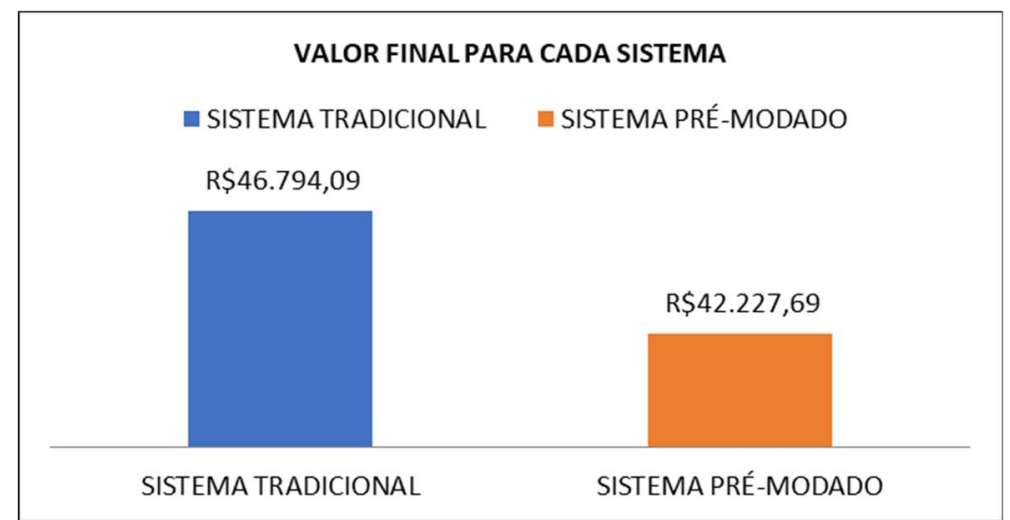

Figura 23: Valor final orçado para os dois sistemas de acordo com o SINAPI.

\section{CONCLUSÕES}

Investir em novas tecnologias é fundamental. Como foi possível observar no decorrer desse trabalho por meio do estudo de alguns autores os quais realizaram estudos entre o método construtivo de prémoldados e o convencional, há algumas vantagens e desvantagens em se utilizar placas pré-moldadas de concreto nas mais variadas regiões do país.

A primeira vantagem que se nota é em relação ao orçamento foi verificado que o método prémoldado reduz a mão de obra e o tempo de execução do empreendimento justamente por dispensar (ou simplificar) algumas etapas constituintes do método tradicional o que, consequentemente, influencia no preço total da obra. Além disso, há uma melhor organização do canteiro de obra, não há consumo excessivo de concreto, uso de formas, entre outros materiais comuns na engenharia civil e que, muitas vezes, reduzindo assim o entulho da obra.

Assim, utilizando o SINAPI foi observado que o método de pré-moldado apresentou uma economia de $9,75 \%$ no valor final. Com base na mesma e diante de tudo o que foi verificado através da análise dos trabalhos dos autores selecionados chega-se à conclusão de que o método de construção de placas prémoldadas, apesar de apresentar algumas desvantagens em relação ao convencional é viável economicamente.

Como principais desvantagens dos elementos pré-moldados (pilares, vigas e painéis) podem-se citar o fato de que precisam ser transportados e erguidos, sem falar que as condições de acesso aos equipamentos não são favoráveis devido ao tipo do transporte, obtendo assim um alto custo. Além do mais, há restrições que dizem respeito à movimentação no canteiro de obras, principalmente se estão localizadas nos centros das grandes cidades, considerando que são necessários equipamentos especiais para este levantamento das peças.

O uso desse método é de grande viabilidade econômica para a região do Tocantins, levando em consideração o SINAPI. Pode suprir o problema da falta de moradia para a população e diminuir gastos no final da construção. Por fim, como complemento da análise da viabilidade do uso de placas pré-moldadas na região, pode-se sugerir pesquisas que envolvam a medição de temperaturas em protótipos ou casas já construídas, tendo em vista as altas temperaturas comuns no estado do Tocantins e buscando analisar o conforto térmico das construções com tal modal construtivo. 


\section{REFERÊNCIAS}

BARBOSA, R. S.. Comparação de custos entre a utilização de alvenaria de blocos cerâmicos e painéis pré-moldados de concreto para construção de unidades habitacionais unifamiliares. Monografia (Bacharelado em Engenharia Civil) - Universidade Federal da Paraíba, João Pessoa, 2018.

EL DEBS, M. K.. Concreto pré-moldado: fundamentos e aplicações. Oficina de Textos, 2000.

PAULANI, F.. A tecnologia das construções em préfabricados de concreto. Monografia (Bacharelado) Universidade São Francisco, Itatiba, 2008.

PIGOZZO, B. N.; SERRA, S. M. B.; FERREIRA, M. A.. A influência dos pré-fabricados em concreto armado no ciclo de industrialização da 25 construção. In: ENCONTRO NACIONAL DE TECNOLOGIA NO AMBIENTE CONSTRUÍDO, 11. Anais. Florianópolis: ENTAC, 2006.

PRODANOV, C. C.; FREITAS, E. C.. Metodologia do trabalho científico: métodos e técnicas da pesquisa e do trabalho acadêmico. 2 ed. Feevale, 2013.

RODRIGUES, W.. A utilização do pré-moldado em edificações residenciais. Monografia (Bacharelado) -
Universidade para o Desenvolvimento do Estado e da Região do Pantanal, Campo Grande, 2018.

ROGOSKI, E. R.. Estudo comparativo entre os sistemas construtivos: alvenaria estrutural e painéis pré-moldados autoportantes de concreto armado. 2018.

ROSÁRIO, A. M. C.. Estudo comparativo de custo entre alvenaria estrutural, paredes de concreto armado e alvenaria em painéis modulares. Construindo, v.9, n.01, 2017.

SOUZA, F. M.; RUFINO, L. M.. Construção residencial unifamiliar em paredes de concreto pré-moldada: comparativo entre métodos tradicional (alvenaria em bloco cerâmicos) e pré-moldados. Monografia (Bacharelado em Engenharia Civil) - Universidade do Sul de Santa Catarina, Tubarão, 2017.

WILK JUNIOR, D.; TARARI, L.. Proposta para projeto de residência unifamiliar padrão CAHAPAR MBP43 adaptada ao uso de painéis pré-fabricados de concreto armado. Monografia (Bacharelado) - Universidade Tecnológica Federal do Paraná, Pato Branco, 2016.

A CBPC - Companhia Brasileira de Produção Científica (CNPJ: 11.221.422/0001-03) detém os direitos materiais desta publicação. Os direitos referem-se à publicação do trabalho em qualquer parte do mundo, incluindo os direitos às renovações, expansões e disseminações da contribuição, bem como outros direitos subsidiários. Todos os trabalhos publicados eletronicamente poderão posteriormente ser publicados em coletâneas impressas sob coordenação da Sustenere Publishing, da Companhia Brasileira de Produção Científica e seus parceiros autorizados. Os (as) autores (as) preservam os direitos autorais, mas não têm permissão para a publicação da contribuição em outro meio, impresso ou digital, em português ou em tradução. 